\title{
Experimental studies on seismic performance of precast steel reinforced concrete frame and connections
}

\author{
Xiang $\mathrm{HU}^{1}$; *Weichen $\mathrm{XUE}^{2,5}$; Yanbo $\mathrm{SUN}^{3}$; Chenguang $\mathrm{LI}^{4}$ \\ ${ }^{1}$ PhD candidate, Department of Structural Engineering, Tongji University \\ ${ }^{2}$ Professor, Department of Structural Engineering, Tongji University \\ ${ }^{3}$ Engineer, Beijing Building Construction Research Institute Co., Ltd., China \\ ${ }^{4}$ Professor of Engineer, Beijing Building Construction Research Institute Co., Ltd., China \\ ${ }^{5}$ Corresponding author's e-mail: xuewc@tongji.edu.cn
}

\begin{abstract}
A new type of precast steel reinforced concrete (PSRC) frame, which were composed of composite steel reinforced concrete (CSRC) beam, PSRC column and cast-in-situ (CIS) joint, were proposed in this paper. The assemble technique used in the ordinary steel structures were adopted in PSRC frames to improve the construction efficiency. The seismic performance of PSRC frame structures was investigated based on the test results of connections and frame. Firstly, full-scale internal connection specimens, including a CIS connection specimen RCJ-1 and a PSRC connection specimen PCJ-1, were tested under low reversed cyclic loading. Results revealed that both the specimens RCJ-1 and PCJ-1 exhibited similar performance in terms of loading capacity, stiffness degradation and energy dissipation. The ductility of specimen PCJ-1 was about 3.81, which was a little lower than the specimen RCJ-1. Then, a 1/3-scale PSRC frame structure specimen, namely PCF-1, was tested under low reversed cyclic loading. Results showed that the PSRC frame specimen PCF-1 was failed in mixed failure mechanism, which provide good energy dissipation capacity. The ductility coefficient of PCF-1 was about 3.45 indicating that the PCF-1 behaved in ductility manner. The results of this investigation could enrich the data available documenting the behavior of PSRC frame, and contribute to enlarge the application of PSRC frame structures in seismic zone.
\end{abstract}

\section{KEYWORDS}

Precast steel reinforced concrete frame; connection; low reversed cyclic loading; ductility; energy dissipation capacity

\section{INTRODUCTION}

In the seismic zone, the most versatile and practical method of connecting precast elements together to form a structural frame is to extend the reinforcing steel from the precast units into the in situ reinforced concrete (Yee, 2001). This method reduces the sensitivity to precast concrete dimensional tolerances and provides structural safety, continuity, and monolithic action at all connections throughout the framing system, but the construction of the precast concrete structures using this method should be moved storey by storey because the structural frame could not be formed unless the construction of connection completed, including connecting of reinforcing bars 
in precast concrete units and casting of in situ concrete (Marvin et al., 1976; Predrag and Popovic, 2000).

In order to speed up the construction of connection which could reduce the period of forming the structural frame, the authors proposed a new type of precast steel reinforced concrete (PSRC) frame. The PSRC frame was composed of composite steel reinforced concrete (CSRC) beam, PSRC column and cast-in-situ (CIS) joint. The assemble technique used in the ordinary steel structures were adopted in the PSRC frames to improve the construction efficiency. The temporary frame structure could be erected without supports and the assemblage construction of upper storeys should not depend on the age of CIS concrete and connecting of reinforcing bars of the lower storeys. As a new type of precast concrete structures, available studies on the seismic performance of PSRC frame structures are almost blank and relevant work should be conducted. As a result, the research panel in Tongji University has conducted systematically experimental studies on seismic performance of PSRC frame structures since 2012. The test results of fullscale connection specimens and 1/3-scale frame specimen under low reversed cyclic loading were presented in this paper.

\section{EXPERIMENTAL PROGRAM Specimen details}

The specimens include two full-scale internal connections and a 1/3-scale frame, which were from an 18-storey prototype frame building in Shanghai, China. Specimens RCJ-1 and PCJ-1 represented CIS and PSRC interior connections respectively. Specimens PCF-1 represented PSRC frame. Fig. 1 and Fig. 2 show dimensions and reinforcement details of the connections and frame. The steel in the precast concrete beams and columns were connected by bolting on the web and welding on the flange. The longitudinal reinforcements in the precast concrete columns were connected by steel sleeves, while the longitudinal reinforcements in the precast concrete beams were connected by welding.

\section{Materials}

Table 1 summarizes the measured properties of the reinforcing bars and steel. The concrete mixture was designed for a cubic compressive strength of $40 \mathrm{MPa}$ for all the specimens. The concrete was vibrated when placed to ensure good workability in the mixture.

\section{Test setup and loading procedure}

The adopted geometry of specimens was determined by the prototype structure as well as the loading space and ground anchors in the laboratory.

The boundary condition of interior connection specimens are presented in Fig. 3(a). The column was supported by a pinned connection at its base (Fig. 3(b)), and the top of the column was free to move. The beam ends were designed as a roller support (Fig. 3(c)). A constant axial load was applied to the column. The axial compressive ratio $n$ was 0.4 . Here, the axial compression ratio $n$, is defined as $n=N /\left(f_{c} \cdot A\right)$, where $N$ is the axial load, $f_{c}$ is the axial compressive strength of concrete and $A$ is the area of column cross-section.

Fig. 4 shows the test setup of frame specimen. It was tested under constant vertical loads (axial compressive ratio was 0.3 for two exterior columns and 0.4 for the middle column). The vertical loads were applied to three column tops by using three identical hydraulic actuators, which could automatically trace the column top when loading to consider the P-delta effect. The lateral loads 
at the first and second storey were applied with a constant ratio 0.5, which reflected the distribution of horizontal seismic force along the structure's height.

Table 1. Properties of reinforcing bars and steel

\begin{tabular}{|c|c|c|c|c|c|}
\hline Type & $\begin{array}{c}\text { Diameter / } \\
\text { Thickness }\end{array}$ & $\begin{array}{c}\text { Yield strength } \\
f_{\mathrm{y}},(\mathrm{MPa})\end{array}$ & $\begin{array}{c}\text { Ultimate strength } \\
f_{\mathrm{u}},(\mathrm{MPa})\end{array}$ & $\begin{array}{c}\text { Elongation at } \\
\text { fracture, } \%\end{array}$ & $\begin{array}{c}\text { Young's modulus, } \\
\mathrm{E}_{\mathrm{s}},\left(\times 10^{5} \mathrm{MPa}\right)\end{array}$ \\
\hline A8 & $8 \mathrm{~mm}$ & 316 & 507 & 25.0 & 2.00 \\
\hline $\mathrm{A} 12$ & $12 \mathrm{~mm}$ & 319 & 467 & 24.5 & 1.87 \\
\hline C8 & $8 \mathrm{~mm}$ & 375 & 685 & 20.0 & 1.80 \\
\hline C10 & $10 \mathrm{~mm}$ & 441 & 605 & 21.0 & 1.93 \\
\hline C14 & $14 \mathrm{~mm}$ & 513 & 636 & 20.0 & 2.09 \\
\hline C16 & $16 \mathrm{~mm}$ & 452 & 632 & 20.5 & 1.86 \\
\hline C20 & $20 \mathrm{~mm}$ & 439 & 588 & 22.5 & 1.93 \\
\hline C25 & $25 \mathrm{~mm}$ & 446 & 598 & 26.5 & 1.93 \\
\hline \multirow{4}{*}{ Q345 } & $14 \mathrm{~mm}$ & 276 & 444 & 25.5 & 1.84 \\
\cline { 2 - 6 } & $10 \mathrm{~mm}$ & 352 & 519 & 20.5 & 1.86 \\
\cline { 2 - 6 } steel & $8 \mathrm{~mm}$ & 386 & 528 & 24.5 & 1.96 \\
\cline { 2 - 6 } & $6 \mathrm{~mm}$ & 300 & 452 & 27.5 & 2.00 \\
\cline { 2 - 6 } & $4 \mathrm{~mm}$ & 367 & 573 & 21.5 & 1.85 \\
\hline
\end{tabular}

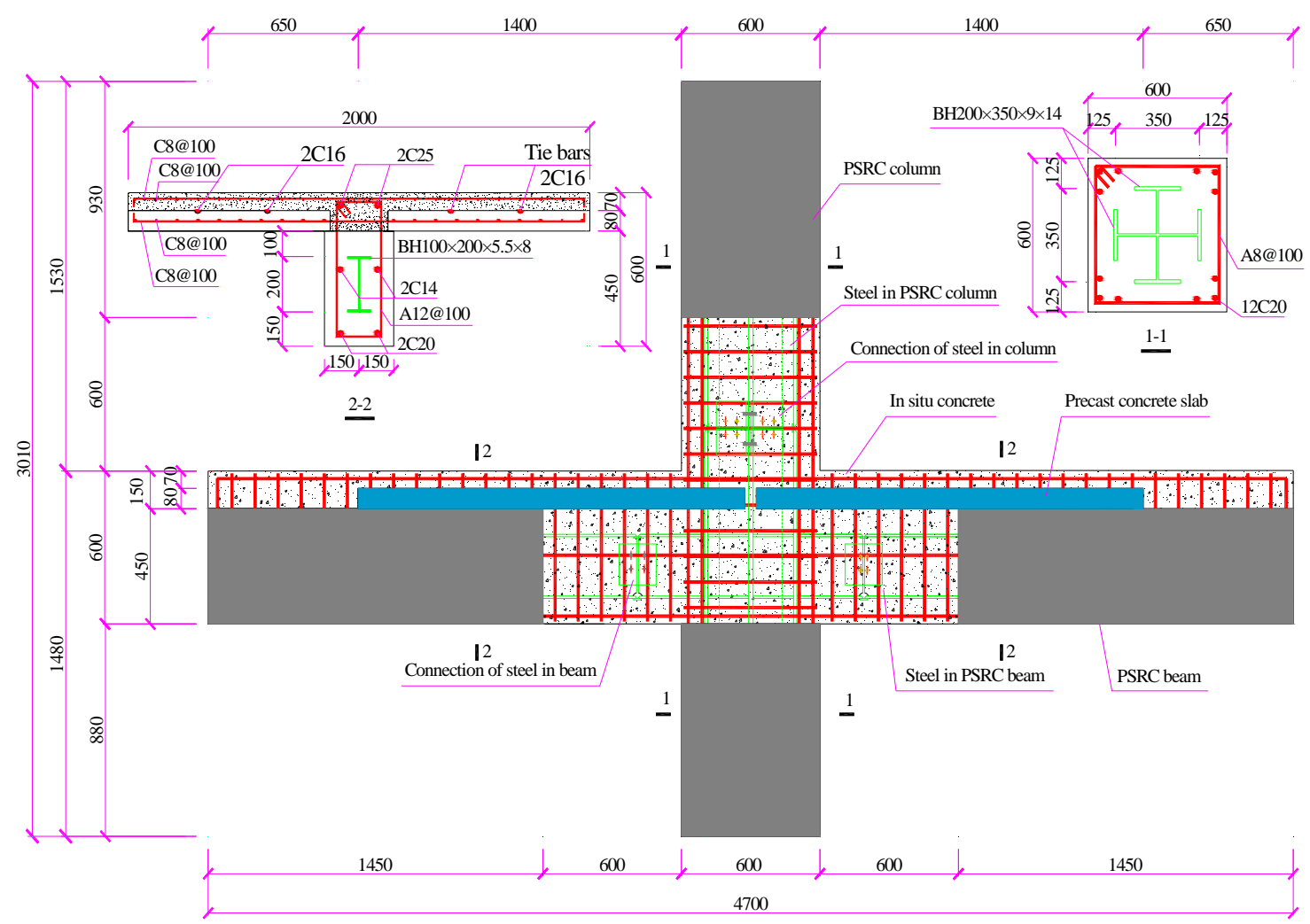

Figure 1. Details of connection specimens PCJ-1 


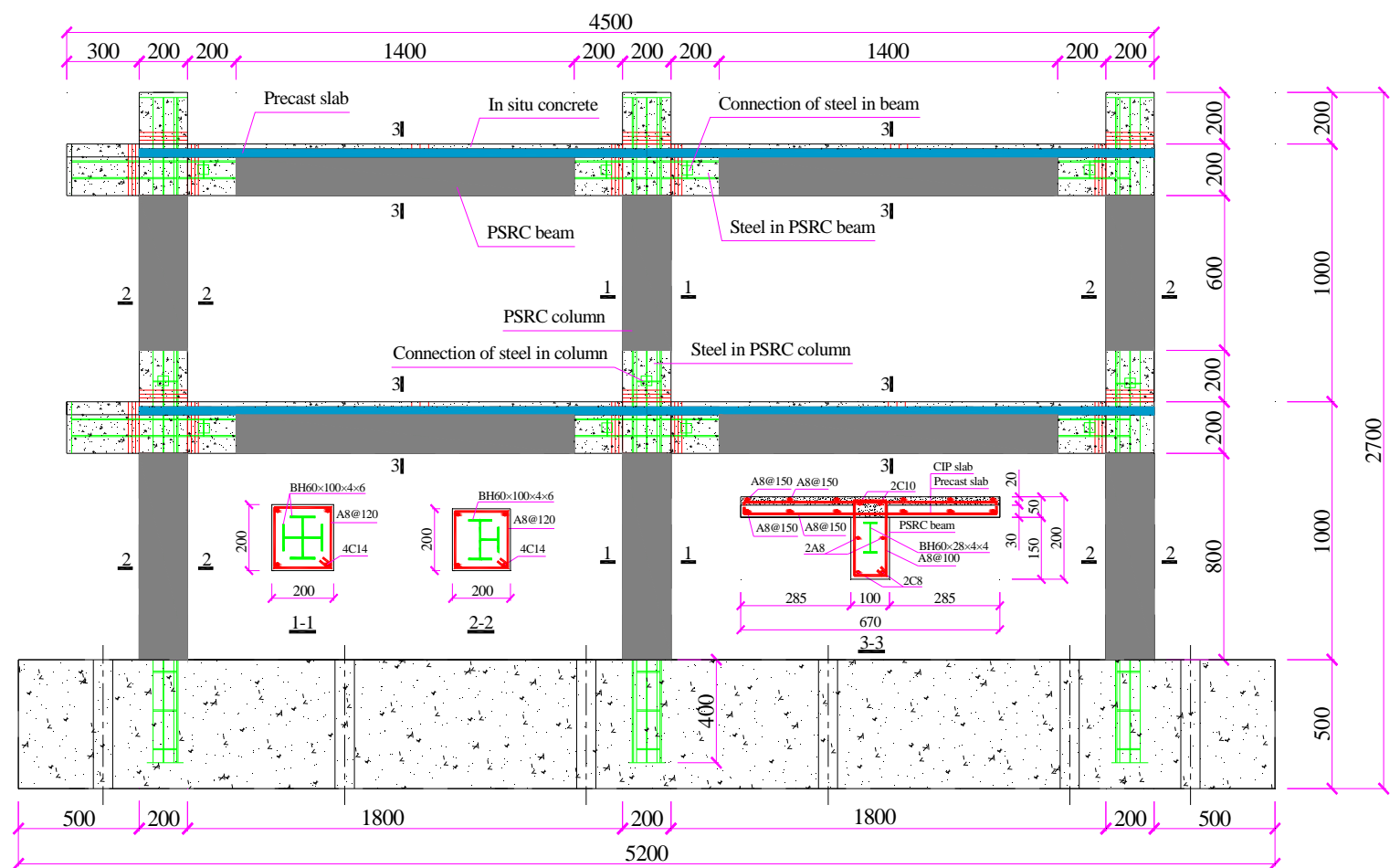

Figure 2. Details of frame specimens PCF-1

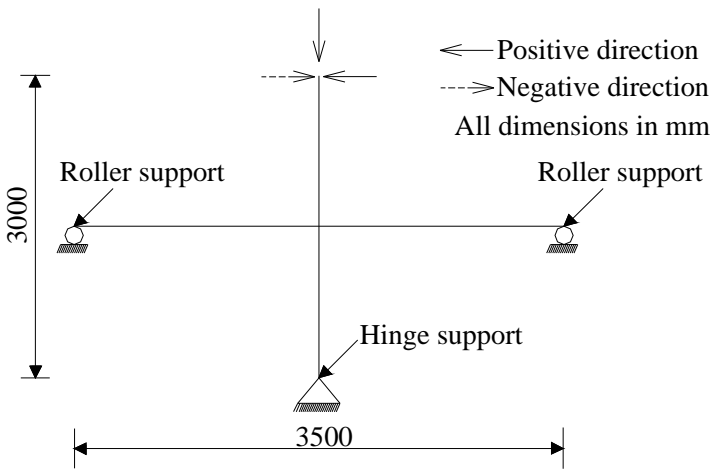

(a) boundary conditions

Column insert in the steel fundation

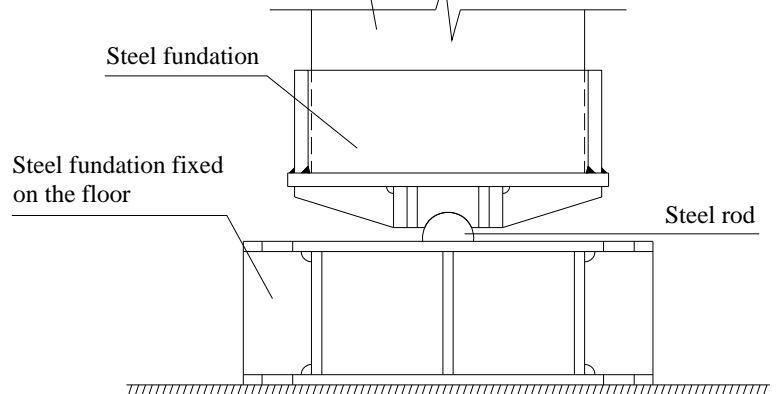

(b) column base boundary condition

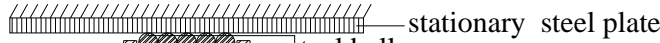

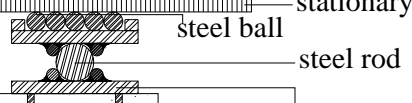
embedded steel plate beam end

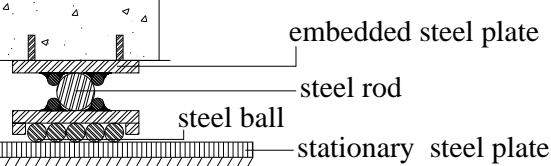

(c) beam end boundary condition

Figure 3. Boundary condition of interior connection specimens 


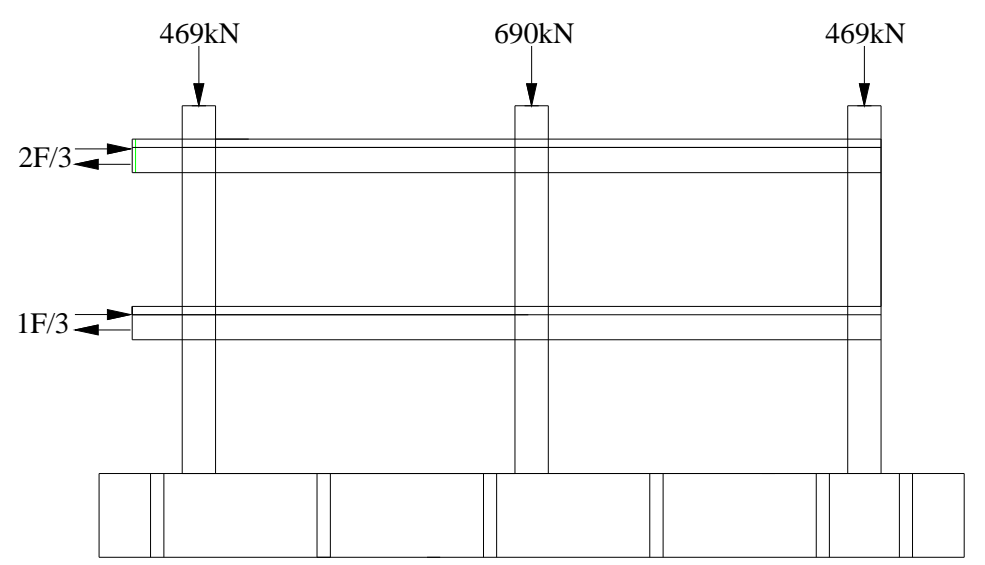

Figure 4. Test setup of frame specimen

The loading history of lateral reversed loads was divided into two phases. The first phase was a load-controlled phase. The second phase was a displacement-controlled phase consisting of cycles of increasing magnitude $0.5 \%$ storey drift, with three cycles applied at each drift level.

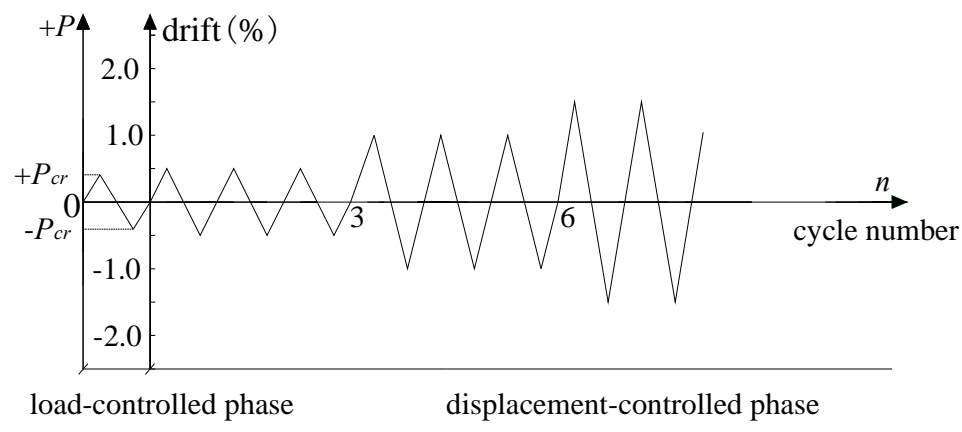

Figure 5. Loading history of lateral loads

\section{EXPERIMENTAL RESULTS AND DISCUSSION}

\section{Failure pattern of connections}

The failure pattern of the connection specimens are shown in Fig. 6. The main characteristics of the failure process and the failure pattern were as follows:

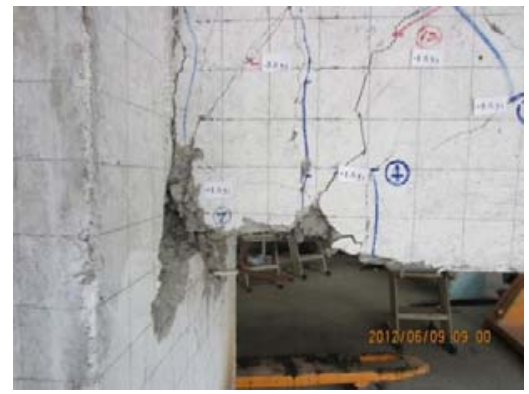

(a) RCJ-1

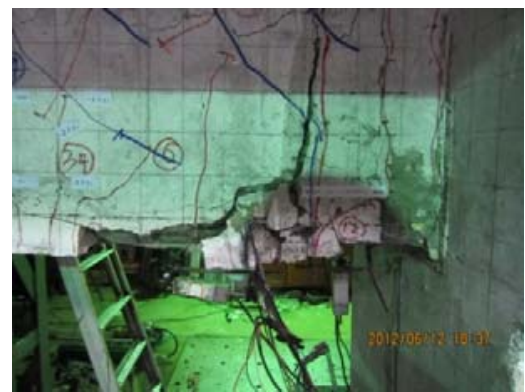

(b) PCJ-1

Figure 6. Failure pattern of the connection specimens 
(1) For CIS connection RCJ-1, the first crack appeared on the beam end at the column face. For PSRC connection PCJ-1, the crack occurred on the interface of the beam and the beam end at the column face early.

(2) At the end of the test, concrete damage was visible in the beam near the face of column, and the reinforcements fractured at the bottom of the beam end. It revealed that both the specimens RCJ-1 and PCJ-1 exhibited a strong column-week beam failure mechanism, and it achieved the design objectives.

(3) The damage did not occurred in the joint region and the column-column interface during the tests, which can proved that the construction details of the joint and the column-column interface were reliable.

(4) The steel in the beams became yielding at the loading stage of $1 \%$ storey drift, while the steel in the columns were not yield in the whole loading procedure.

\section{Failure pattern of frame}

The failure pattern of frame specimen is shown in Fig. 7. The main characteristics of the failure process and the failure pattern were as follows:

(1) The first plastic hinge formed at the first-storey beam end. After developing at the beam ends to some extent, the plastic hinge finally began to occur at the column ends.

(2) The frame failed in mixed side-sway mechanism and the failure pattern of the frame was characterized by concrete crushing and buckling of longitudinal bars at the fixed column bases.

(3) Same as the connection specimens, the steel in the beams were yield after the $1 \%$ storey drift loading, while the steel in the columns were not yield in the whole loading procedure.

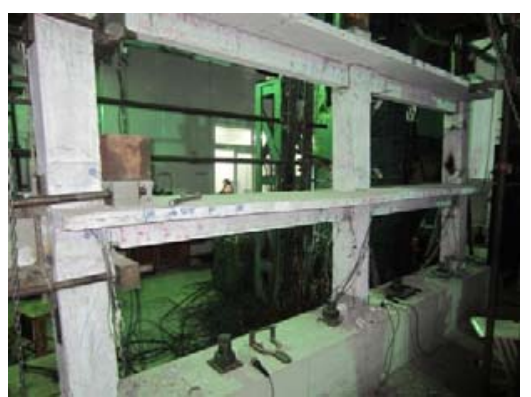

Figure 7. Failure pattern of the frame specimen

\section{P-delta hysteretic response}

Fig. 8 and Fig. 9 show the lateral load vs. storey displacement hysteresis curves of connections and frame, respectively.

At the earlier loading stage, the connections exhibited a stable hysteretic response, and then slight pinching could be observed in the hysteresis loops due to beam end cracking and joint diagonal cracking. The areas of hysteresis loops became larger gradually as storey drift increased, indicating good energy dissipation capacity.

Frame specimen PCF-1 exhibited a stable load versus drift hysteretic response, and the areas of hysteresis loops became larger gradually with increasing roof drift, showing good energy dissipation capacity. The maximum load of the first cycle was higher than that of other two cycles at the same drift level, showing strength degradation. 


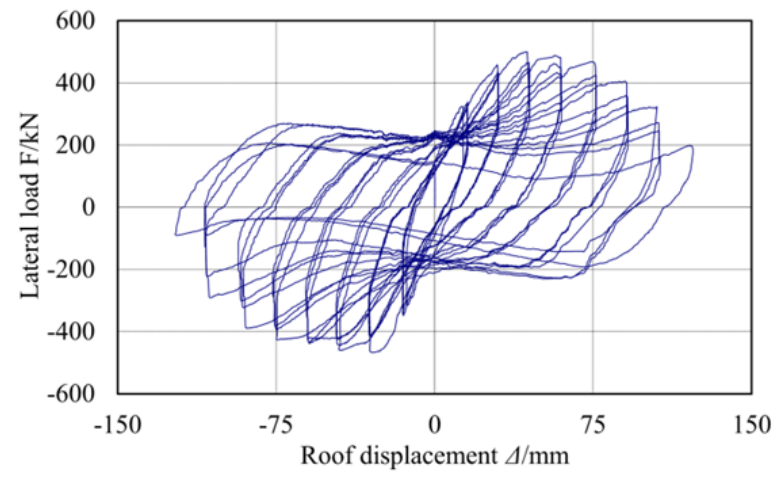

(a) RCJ-1

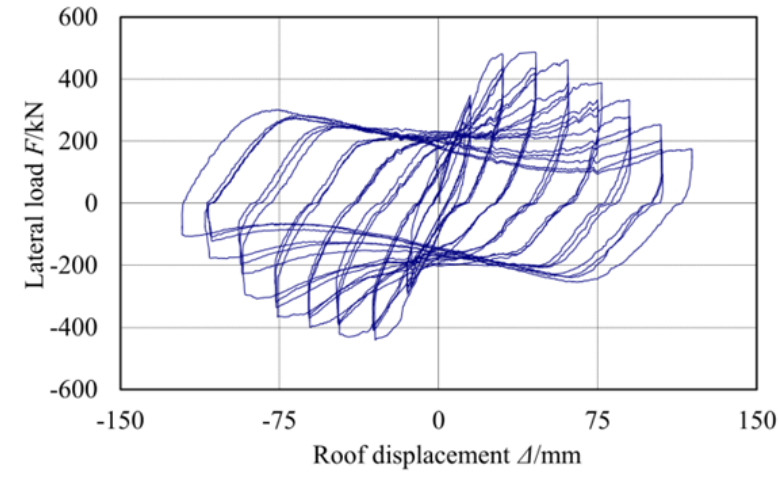

(b) PCJ-1

Figure 8. Hysteresis curves of connection specimens

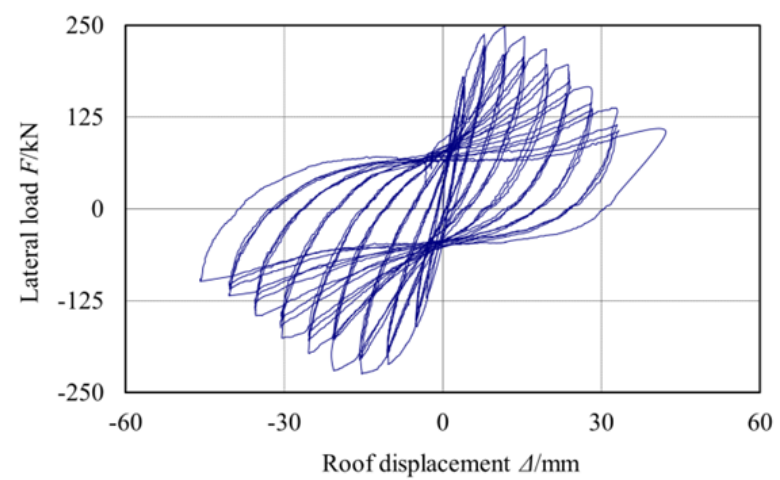

Figure 9. Hysteresis curves of frame specimen

\section{Displacement ductility}

The lateral load vs. displacement envelope curve was used to define the yield displacements according to the criteria for equivalent elasto-plastic energy absorption used by Park (1989). The ultimate displacement, $\Delta_{\mathrm{u}}$, was determined as corresponding to a $15 \%$ drop of the lateral peak load. The displacement ductility coefficients of all the connection and frame specimens are listed in Table 2.

The results in Table 2 indicate that both the CIS and PSRC connections exhibited excellent ductile manner. The average ductility coefficient of PCJ-1 was 3.81, which was a little lower than that of RCJ-1. The global ductility coefficient of PSRC frame specimen PCF-1 was 3.45, indicating that the PSRC frame behaved in ductile manner.

Table 2. Characteristic loads and displacement ductility

\begin{tabular}{|c|c|c|c|c|c|c|c|c|c|c|}
\hline \multicolumn{2}{|c|}{ Specimen } & $\begin{array}{c}P_{\mathrm{cr}} \\
(\mathrm{kN})\end{array}$ & $\begin{array}{c}\Delta_{\mathrm{cr}} \\
(\mathrm{mm})\end{array}$ & $\begin{array}{c}P_{\mathrm{y}} \\
(\mathrm{kN})\end{array}$ & $\begin{array}{c}\Delta_{\mathrm{y}} \\
(\mathrm{mm})\end{array}$ & $\begin{array}{l}P_{\max } \\
(\mathrm{kN})\end{array}$ & $\begin{array}{c}\Delta_{\max } \\
(\mathrm{mm})\end{array}$ & $\begin{array}{c}P_{\mathrm{u}} \\
(\mathrm{kN})\end{array}$ & $\begin{array}{c}\Delta_{\mathrm{u}} \\
(\mathrm{mm})\end{array}$ & $\Delta_{\mathrm{u}} / \Delta_{\mathrm{y}}$ \\
\hline \multirow{2}{*}{ RCJ-1 } & POS & 199.9 & 3.1 & 370.8 & 19.2 & 499.2 & 43.8 & 424.3 & 85.9 & 5.55 \\
\hline & NEG & 140.3 & 2.2 & 412.2 & 20.4 & 464.5 & 30.4 & 394.8 & 85.5 & 5.84 \\
\hline \multirow{2}{*}{ PCJ-1 } & POS & 160.2 & 3.7 & 358.3 & 18.1 & 485.1 & 45.8 & 412.3 & 70.7 & 7.16 \\
\hline & NEG & 120.9 & 2.3 & 380.4 & 18.4 & 432.4 & 30.0 & 367.5 & 68.0 & 6.61 \\
\hline \multirow{2}{*}{ PCF-1 } & POS & 15.0 & 0.3 & 219.6 & 15.4 & 248.2 & 31.2 & 211.0 & 54.2 & 3.5 \\
\hline & NEG & 20.0 & 0.8 & 193.6 & 16.0 & 221.9 & 30.5 & 188.6 & 54.0 & 3.4 \\
\hline
\end{tabular}

Note: POS—positive direction; NEG—-negative direction 


\section{Stiffness degradation}

The secant stiffness of connection specimens and frame specimen are plotted against roof displacement in Fig. 10. The followings could be concluded from the figures:

(1) The stiffness of each specimen continuously decreased as displacement increased and was close to zero at the end of test.

(2) The stiffness degradation trend of the PSCR connection was very similar to that of the CIS connection.

(3) For both connection specimens and frame specimen, stiffness degraded rapidly before the drift of $1 \%$, which was probably because most concrete cracking and reinforcement yielding occurred in this stage.

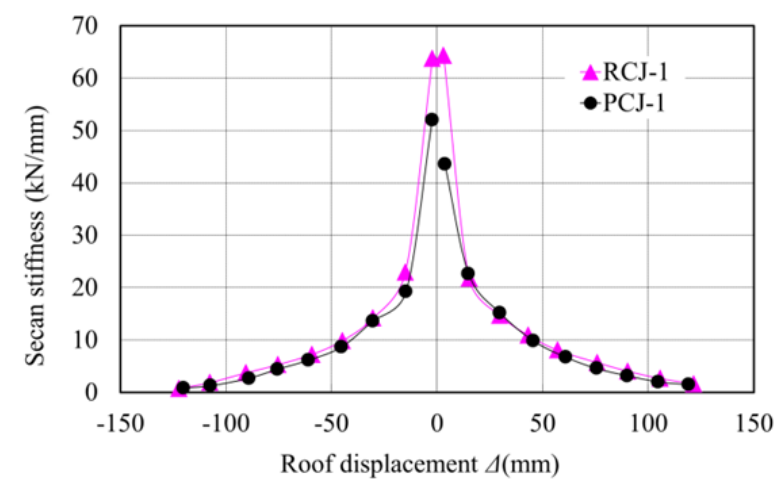

(a) connection specimens

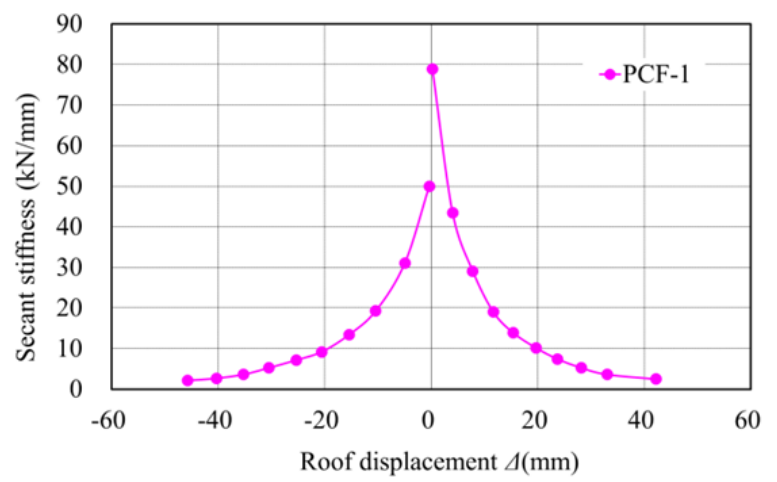

(b) frame specimen

Figure 10. Curves of secant stiffness vs. roof displacement

\section{Energy dissipation capacity}

The energy dissipation capacity is a function of the area under the load-displacement curve and indicates the degree of effectiveness of the connection to withstand earthquake loading. The cumulative energy dissipated of connection specimens and frame specimen is given in Fig. 11.

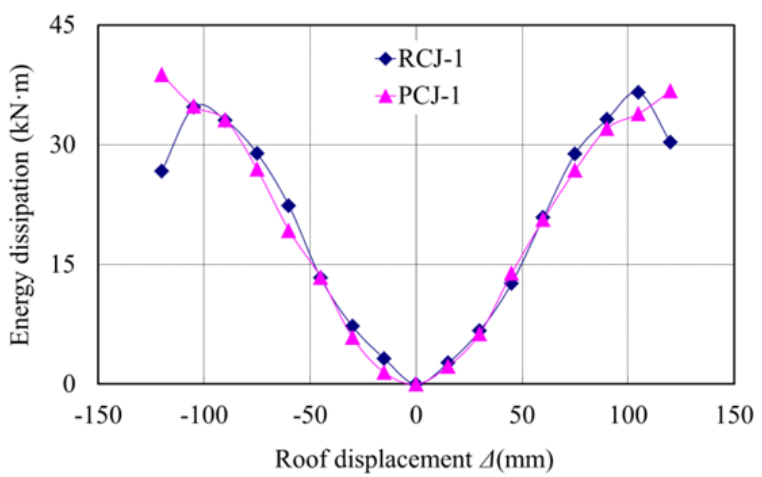

(a) connection specimens

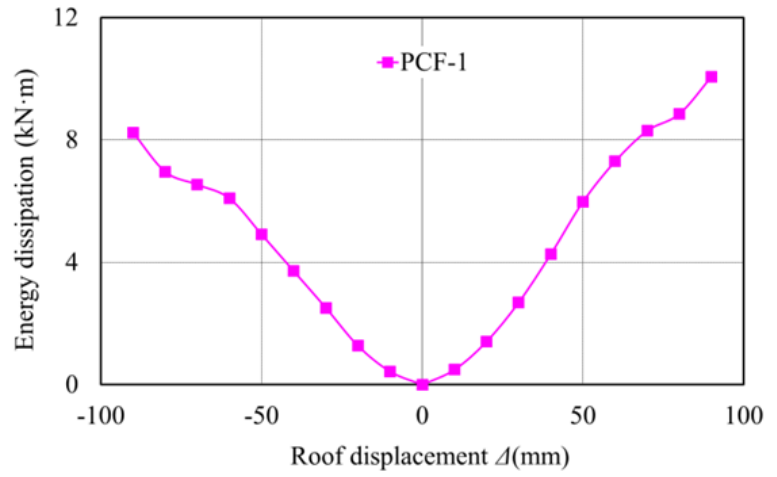

(b) frame specimen

Figure 11. Cumulative energy dissipated of connection specimens and frame specimen

Both the CIS and PSRC connections exhibited similar patterns of energy dissipation. The energy dissipation capacity of all the test specimens, including connections and frame, increased as the displacement increased. The amount of the dissipated energy of the specimens increased with the increasing damage. After reaching the peak load, the load-carrying capacity of the specimens began to gradually decrease, but the energy dissipation capacity still slowly increased. 


\section{CONCLUSION}

There were two connections and a frame tested in this paper to investigate the seismic performance of PSRC frame. Based on the test results, some conclusions were drawn:

(1) The connections developed plastic hinge in the beam ends at the column face without damage in the column and joint region, and exhibited a strong column-weak beam failure mechanism. The design intention was achieved.

(2) The PSRC frame failed in mixed side-sway mechanism and the failure pattern of the frame was characterized by concrete crushing and buckling of longitudinal bars at the fixed column bases.

(3) Both the connections and frame exhibited a stable lateral load vs. drift hysteretic response. The hysteresis curve of PSRC connection specimen was quite similar to that of CIS connection specimen.

(4) The displacement ductility coefficient of PSRC connection was 3.81 and very similar to that of the CIS connection. The global ductility coefficient of PSRC frame specimen PCF-1 was 3.45. The ductility coefficients of connections and frame show that both the PSRC frame structures behaved in a ductile manner

(5) For both CIS and PSRC connections, the trend of stiffness degradation and energy dissipation is similar.

(6) PSRC connections and frame can perform satisfactorily in seismic conditions with respect to strength, ductility, and energy dissipation capacity.

Note that the PSRC frame structures proposed in this paper have been applied in real project in China, and the results have been involved in Shanghai design code "Code for design of monolithic precast concrete public buildings (DGJ 08-2154-2014)”.

\section{ACKNOWLEDGEMENTS}

The authors gratefully acknowledge the financial support provided by the project of Shanghai Science and Technology Commission (No. 14DZ1208302), the program for New Century Excellent Talents in University (No. NCET-10-0636) and the Fundamental Research Funds for the Central Universities.

\section{REFERENCES}

Alfred, A. Yee (2001). "Structural and Economic Benefits of Precast/Prestressed Concrete Construction.” PCI Journal, 46(4), 34-42.

Marvin, L., Vander, H. and Carl Walker (1976). “Tolerances for Precast Concrete Structure.” PCI Journal, 21(4), 44-57.

Park, R. (1989). "Evaluation of Ductility of Structures and Structural Assemblages from Laboratory Testing." Bulletin of the New Zealand National Society for Earthquake Engineering, 22(3), 55-166.

Predrag, L. Popovic, P.E. (2000). "Structural Failures at Concrete-Steel Framing Connections.” Forensic Engineering, 513-522. 